\title{
Marketing Digital e Turismo: Uso de Websites para Atração de Turistas nos Municípios do Rio Grande do Sul/ Brasil
}

\author{
Marketing digital y turismo: uso de sitios web para la atracción de turistas \\ en las ciudades de rio grande del sur/ brasil
}

\author{
Dra. Dalva Maria Righi Dotto ${ }^{1}$; Dra. Mônica Elisa Dias Pons²; Adriele Carine Menezes \\ Denardin³; Lúcio de Medeiros Ruiz ${ }^{4}$ \\ 1 dalvadotto@gmail.com, Universidade Federal de Santa Maria; ${ }^{2}$ monica@ufsm.br,
} Universidade Federal de Santa Maria; ${ }^{3}$ dricadenardin@ hotmail.com, Universidade Federal de Santa Maria; ${ }^{4}$ luciodmruiz@ gmail.com, Universidade Federal de Santa Maria.

\begin{abstract}
Resumo
Com a utilização cada vez mais frequente da internet na busca de informações para a escolha dentre as opções de turismo disponíveis, a otimização dos websites turísticos por parte dos municípios pode ser uma ferramenta importante para o desenvolvimento do turismo. Informações claras sobre os atrativos turísticos facilitam aos turistas escolher o destino, assim como informações sobre a disponibilidade de hotéis e, também, a gastronomia que o local oferece. Com o objetivo de analisar qualitativamente os websites de municípios do Rio Grande do Sul, este estudo, através de uma pesquisa exploratória, pretende disponibilizar aos gestores um diagnóstico comparativo, no intuito de auxiliar na visibilidade do atrativo turístico e sensibilização dos turistas potenciais, para incremento do setor e da economia local.
\end{abstract}

Palavras-chave: Marketing digital, Turismo, Atração Turística, Políticas Públicas.

\section{Contextualização}

O turismo, como atividade produtiva globalizada é resultado, segundo Beni (2003) do aumento da liberalização do comércio mundial, da incorporação de novas tecnologias, da integração horizontal e vertical das empresas de turismo, da difusão territorial do consumo e da flexibilização do trabalho nos diversos setores produtivos. Os números são representativos em relação a quantidade de pessoas que viajam. Segundo a Organização Mundial de Turismo (OMT), agência especializada da ONU, numa tendência de aumento que já dura cinco anos, em 2014, 1,13 bilhão de pessoas viajou a outros destinos internacionais, 51 milhão a mais que em 2013 (OMT, 2015). As principais motivações dos turistas são a necessidade de repouso, diversão, lazer e conhecer e interagir com novas culturas (MONTEJANO, 2001). Segundo o autor, para melhor atender os consumidores, pode-se segmentar os turistas em (a) turismo individual; (b) turismo de massas; (c) turismo itinerante; e, (d) turismo de estada ou residencial.

$\mathrm{Na}$ atração de turistas uma ferramenta importante é o marketing que, segundo American Marketing Association (2009) é a atividade, conjunto de instituições e processos para criar, comunicar, entregar e trocar ofertas que tenham valor para consumidores, clientes, parceiros e sociedade em geral. Devido às características do produto turístico, o marketing para o setor acompanha as estratégias de marketing estabelecidas para os serviços que incluem a intangibilidade, a inseparabilidade, a heterogeneidade e a perecibilidade (HOFFMANN e BATESON, 2010). Considerando essas peculiaridades, a comunicação dos produtos turísticos torna-se relevante, sendo que esta deve ser utilizada para informar, 
persuadir, ou lembrar as pessoas sobre o serviço que está sendo oferecido, pois não há possibilidade de alguém escolher adquirir um produto/serviço que desconhece.

Dentre as formas de comunicação, no setor de turismo a internet tornou-se o meio mais utilizado no processo de decisão do consumidor. Segundo Tomikawa (2010, p. 54),

hoje, qualquer pessoa pode acessar websites de viagem (revendedores e distribuidores), ou até mesmo os próprios fornecedores (linhas aéreas, locadoras de carro, etc.), pesquisar preços e fazer sua própria reserva online, em minutos, além de poder realizar uma viagem virtual ao local que deseja conhecer, já que praticamente todos os destinos têm páginas na web.

Com esta constatação, os municípios que pretendem atrair turistas devem incluir em suas políticas públicas a prerrogativa de utilização da internet, através de Site ou Website, como um espaço para disponibilizar texto, fotos, animações gráficas, sons e vídeos. Também deve organizar a informação ao turista de modo lógico e coerente, estruturando para que o conteúdo tenha fácil acesso e com detalhamento para entendimento completo dos atrativos turísticos e dos serviços ofertados para comodidade do turista. Os websites eficazes contém o que Torres (2010, p.12) denomina de marketing de conteúdo, definido como "o conjunto de ações de marketing digital que visam produzir e divulgar conteúdo útil e relevante na Internet para atrair a atenção e conquistar o consumidor online". Para o autor, é preciso planejar e definir com clareza o conteúdo, através da definição do público-alvo, da análise das pretensões e do comportamento deste público e do conhecimento das informações buscadas para produzir um conteúdo que atenda de forma plena os desejos destes consumidores.

\section{Objetivo}

O objetivo do estudo é analisar qualitativamente os sites oficiais de turismo de municípios do Rio Grande do Sul e, mais especificamente, sistematizar os dados encontrados nos websites, realizando uma análise comparativa para identificar fragilidades e potencialidades.

\section{Metodologia}

O método escolhido para atingir os objetivos deste estudo é a pesquisa exploratória, com análise qualitativa e comparativa do conteúdo dos websites dos municípios gaúchos. Os municípios são selecionados com base no Plano de Desenvolvimento do Turismo do Rio Grande do Sul: 2012-2015, que dividiu o Estado em 11 regiões e 23 microrregiões (SETEL, 2015; SETUR, 2015). A amostra inclui o município que apresentar maior número de habitantes em cada microrregião, o que totaliza 23 municípios.

\section{Resultados}

Constata-se que há muitas deficiências nos websites dos municípios gaúchos, principalmente relacionadas à inexistência de informações sobre pontos turísticos, eventos, roteiros, locais de hospedagem, etc. Também, numa análise preliminar, se observa que, quando há informação ao turista, esta carece de detalhamento e de possibilidade de interação para contato em caso de dúvidas. 


\section{Conclusão}

Com uma análise mais abrangente e comparativa do conteúdo dos websites será possível a verificação de fragilidades a serem corrigidas e potencialidades a serem exploradas pelos gestores municipais, no intuito de definir políticas públicas eficazes para atrair mais turistas e, em consequência, dinamizar a economia dos municípios.

\section{Referências}

BENI, M.C. Análise Estrutural do Turismo. São Paulo: Senac, 2003.

DIAS R.; CASSAR M. Fundamentos do marketing turístico. São Paulo: Prentice Hall Brasil, 2005.

HOFFMANN, K.; BATESON, J. Princípios do marketing de serviços, São Paulo: Pioneira/ Thompson Learning, 2010.

MONTEJANO, J.M. Estrutura do mercado turístico. São Paulo: Roca, 2001.

OMT - Organização Mundial de Turismo. Disponível em http://www2.unwto.org/. Acesso em 06 de junho de 2015.

SETEL/RS. Disponível em http://www.setel.rs.gov.br. Acesso em 06 de junho de 2015. SETUR/RS. Secretaria de Turismo do Rio Grande do Sul. Disponível em http://www.turismo.rs.gov.br. Acesso em 06 de junho de 2015.

TOMIKAWA, J.M. Marketing turístico e internet: uma análise dos sites oficiais de turismo dos estados brasileiros. Dissertação (Mestrado Profissional em Turismo).

Universidade de Brasília, 2010.

TORRES, C. Guia Prático de Marketing na Internet para Pequenas Empresas, 2010.

Disponível em: <http://www.claudiotorres.com.br/mktdigitalpequenaempresa.pdf $>$. Acesso em: 24 out. 2015. 